\title{
Comparison of cultures in consultant and contractor organizations in construction industry
}

\author{
Raufdeen Rameezdeen \\ Nishanthi Gunarathna
}

\begin{abstract}
Large number of stakeholders in construction projects makes the construction industry prone to disputes. The historical separation between design and construction add to this phenomenon by having a consultant for design and a contractor for construction. Communication breakdown, frequently, is the first sign of problems, notably in the relationship between the Contractor and the Consultant. It appears that the split between design and construction has given rise to two separate cultures in the construction industry. This paper attempts to identify whether there is a difference in organizational culture between Consultants and Contractors taken as two groups and determine whether a specific attribute was related to the cultural differences between the two entities. Based on case studies it was found that consultants are biased towards Clan culture while contractors are biased towards Market culture. However, both groups show similar affinity to Adhocracy and Hierarchy cultures.
\end{abstract}

\section{Introduction}

The common practice used in procuring construction in Sri Lanka as well as many other countries could be explained using a model termed "tripartite system". Three parties are the Employer, the Consultant and the Contractor whose mutual responsibilities are defined by contractual and professional obligations. The formal nature of this relationship dates back to the colonial rule in Sri Lanka, and is regarded by its practitioners as the key to prudent project implementation in a market economy. It is designed to secure value for money through commercial competition, while protecting the legitimate interests of public finance and all concerned.

The term Employer covers the initiating agency, which is responsible for providing funds for the execution of a project. The Employer inexperienced in the design and implementation of construction works seeks the advice of the Consultant. The Consultant is normally given two tasks by the Employer, the recommendation and justification of a preferred technical proposal together with an estimate of its cost, and further refinement of the design to the stage where tenders can be called for construction and the framework for site supervision can be established. Based on the competitive tendering system, a Contractor is selected for the physical execution of the project. Responsibilities of the Contractor relate to the implementation of works specified in a formal contract, based on the Consultant's designs. The relationships between the Employer - Consultant and the Employer - Contractor are governed by a formal contract. However, the relationship between the Consultant - Contractor is just a functional one, which does not have contractual implications. However, during the implementation stage of a project, Consultant - Contractor relationship is very crucial. This historical separation between design and construction is well documented and considered as a main reason for the problems encountered in the construction industry (Egan, 1998; Bennett et.al., 1996; Seymour and Rooke, 1995; Latham, 1994).

A preliminary investigation of disputes in the Sri Lankan construction industry was conducted to determine the root causes. This indicated that communication gap between the Consultant and Contractor as the main reason for most of the disputes (Fernando, 2002). Therefore, it appears that the split between design and construction activities has given rise to two separate cultures in the construction industry on which these two entities operate. They work in watertight compartments and very few things can be seen in common. The desire to bring design and construction activities together, is well established and has been generally welcomed by the industry (Root and Hancock, 1996). However this is seen primarily as a redesign of the construction process through new contractual relationships, procurement routes and management tools (Seymour and Rooke, 1995). Rameezdeen and De Silva (2002) have shown that adoption of these new procurement methods is diffiult in countries like Sri Lanka where traditional method is well established. They estimated that $85 \%$ of construction projects are still procured through the traditional method. It is increasingly accepted that "Culture "as a major factor that hinders the integration of design and construction (Latham (1994), Egan (1998) Root and Hancock (1996)). 
The objective of this paper is to investigate whether there is a difference in organizational culture between Consultants and Contractors taken as two groups and to determine whether a specific attribute was related to the cultural differences between the two entities. The research hypothesis to be tested is that:

"There is a difference in organizational culture between Consultants and Contractors taken as two groups and this difference is due to some identifiable attributes".

It is important to note that the focus of this paper is limited to the organizational culture, which is narrow in scope compared to the culture taken as a whole.

\section{Organizational culture}

Organizational culture is identified as "a collective programming of the mind which distinguishes the members of one organization from another" (Hofstede, 1984). There is no doubt that different organizations develop different cultures. Sometimes it is fragmented and difficult to read from the outside. Culture has two basic components namely, substance and forms (Trice and Beyer, 1984). Substance is the work practices, which contained in organizational values, norms and beliefs. On the other hand, forms are expressed, affirmed, and communicated to the members of the organization.

The culture in an organization is analogous to personality in an individual. Deal \& Kennedy (1982) suggested that culture was the element that explained why companies were differed so greatly, even those in the same industry. Most successful organizations have developed something special that supersedes corporate strategy, market presence or technological advances - a distinctive culture. Byar (1987) pointed out four factors that contribute to the origin of an organization's culture as its history, environment, staffing process and socialization process. Since all organizations must interact with their environment, the environment plays an important role in shaping an organization's culture. Organizations that operate within a highly regulated environment develop cultures totally different from organizations that face fierce competition in industries with rapidly changing technology.

Without valid means of measuring organizational culture, research into culture and its relationship with various factors and the environment is not possible. Further, it is essential to relate or link the measure to the business environment, especially in an industry like construction. Bowers (1969) highlighted five variables that composed culture and highlighted communication as being the most significant. Harrison (1972) proposed a model consisting of four basic variables. Hofstede's (1991) studies on organizational culture identified six independent dimensions of practices and Deal and Kennedy (1982) classified organizational culture on the basis of two aspects as degree of risk associate with the organizational activities and speed with which organizations and their employees get feedback indicating the success of decision. They identified four basic culture types according to their categorization. Lundberg (1990) suggested six basic ingredients as representing culture. Maloney (1989) and Maloney and Federle (1991) presented a framework developed by Quinn (1988)and Cameron (1984) in terms of organizational culture, organizational effectiveness, leadership roles, and management skills. Further, they presented the results of a study of organizational assessment that used a framework of competing values (Maloney and Federle,1993), developed by Quinn and Cameron and proved that the methodology is valid. Hence, Competing Value Framework developed by Quinn and Cameron is a promising model for the measurement of organizational culture. This model is used in this study to determine the cultural differences between Consultants and Contractors in Sri Lanka.

The Quinn and Cameron approach is lo ask the respondents to describe the organization by how it functions, i.e.,to describe the behaviors exhibited within the organization. Based upon the description, the organizational culture is placed within a 'framework of cultures'. Results indicate perceptions of employees on their organization. As shown in Figure1, the model dichotomizes four different organizational culture types into a $2 \times 2$ matrix. There are four organizational culture types, namely Clan, Adhocracy, Market and Hierarchy. The axes for the quadrants illustrate the concept of Competing Values, in which the organizational culture types on the diagonals are 'competing' and those adjacent are 'complimentary'.

Organizations having a bias towards upper half of the figure are considered to be oriented towards the decentralization and differentiation, with an emphasis on spontaneity and flexibility. Organizations having a bias towards bottom of the figure rely upon centralization and integration, with an emphasis on predictability and order. Organizations, which are biased towards left side of the figure, emphasize maintenance of socio-technical system, have an internal focus, and utilize a long-term horizon. Organizations biased on right side of the figure are oriented towards the competitive position of the overall system, have an external focus, and operate with short-term horizons. Thus, the values of the left side are competing with those of the right side. 
Quinn (1988) describes the four organizational culture types that can exist in any organization with different compositions as follows.

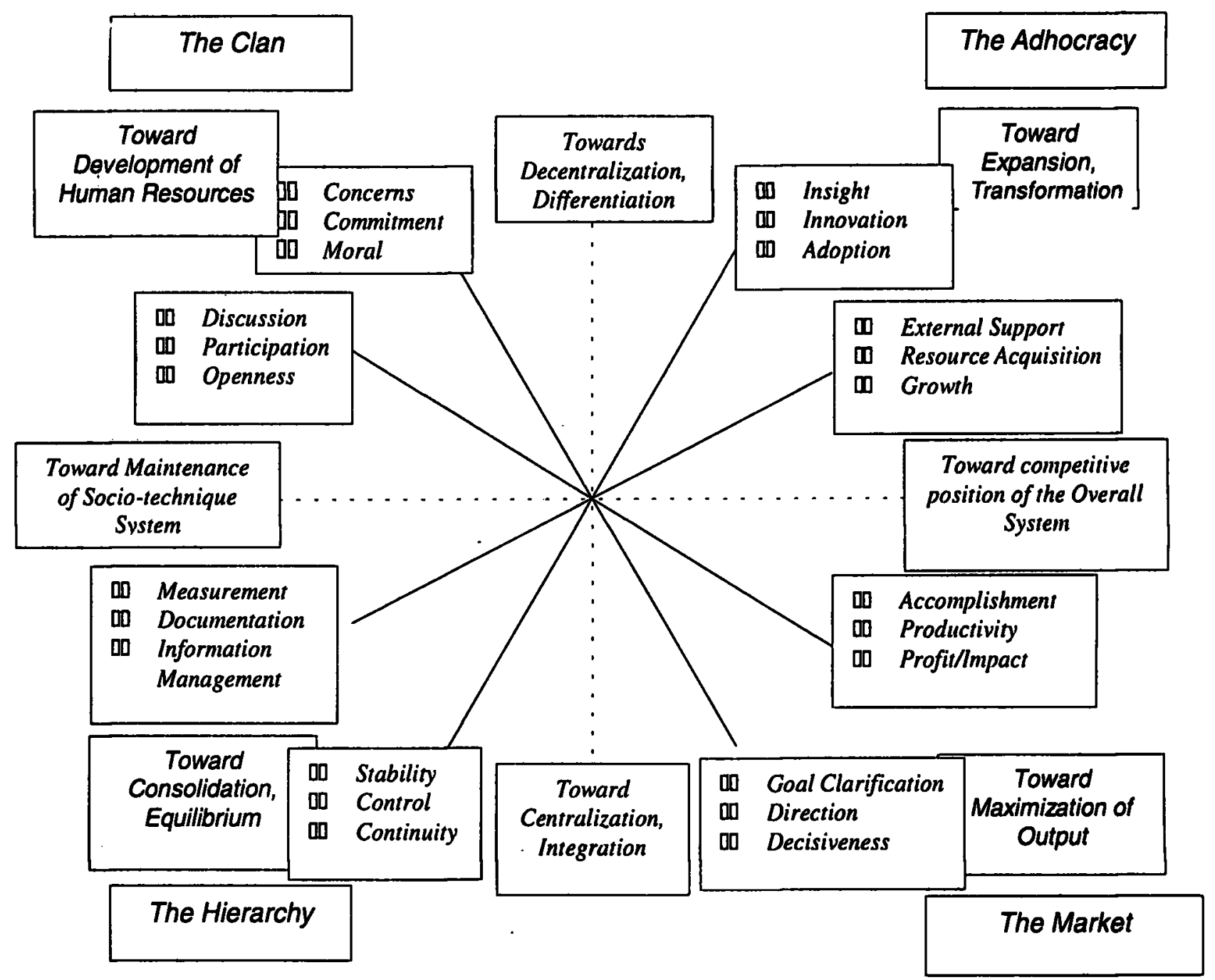

Fig 1: Competing value framework for organization: culture (Quinn, 1988)

\subsection{Clan Culture}

Clan culture is in the upper-left quadrant of the figure. It values emphasizing openness, participation and discussion. The objective is to get everyone involved in activities and decisions of the organizations. Members of the organization have a concern for other members and the organization has a commitment to its members and their morale. Rewards are based upon group and organizational performance rather than individual performance. The organization come before the individual, who is a member of a team committed to the advancement of the organization. The clan emphasizes flexibility and individual deferences. It is characterized by teamwork and information sharing.

\subsection{Adhocracy Culture}

The upper-right quadrant of the figure is labeled as the Adhocracy culture. It prizes external support, resource acquisition, and growth that it obtains through insight, innovation, and adaptation. The emphasis is on innovation, looseness, and flexibility of structure in conjunction with a focus on external constituencies and resource providers and the achievements of legitimacy with outside stakeholders. Distinguishing features of the Adhocracy includes the prominence of entrepreneurial activity, creativity, and acquiring resources from extemal providers. There is a commitment to risk, innovation, and development.

\subsection{Market Culture}

Market is the term employed for the culture of a rational goal model organization. This can be identified in lowerright quadrant of the figure. With its emphasis on the maximization of output, Market culture value goal clarification, providing direction, and being decisive about what is to be done. It prides itself on accomplishment and productivity and in making a profit or having an impact. It emphasizes order, rational production, and goal accomplishment in combination with external interactions with suppliers, customers, subcontractors and competitors. The competitive orientation towards rivals and emphasis on achievements on the market place distinguish the Market from other cultures. 
Members of the organization are clearly instructed by a decisive, authoritarian leader and are rewarded financially, if they perform well. Rewards are based on individual performance rather than organizational performance.

\subsection{Hierarchy Culture}

The hierarchy or bureaucratic culture is characteristic of the internal process and is based on consolidation and equilibrium. It is the antithesis of the Adhocracy culture. Hierarchy culture values stability, control, and continuity, which are obtained through measurement, documentation, and information management. Maintenance of internal system is of paramount importance. People are given well-defined roles and are expected to follow the rules and procedure that are developed to govern their actions. Situations are structured to fit the rules and procedures of the organization. The major reward for the performance within the Hierarchy culture is job security. Financial rewards are primarily seniority based.

\section{Cultural elements of an organization}

Organizational culture can be considered as a cumulative representation of an assortment of elements. Quinn \& Cameron identified six elements within the organization to represent culture. These elements are briefly as follows.

\section{Dominant characteristics of the organization}

Dominant characteristics can be considered as core values of the organization. Clan culture values the importance of human resources while Market culture highlights the importance of exercising productionrelated strategies. Adhocracy culture place emphasis on enterpreneurship and core values of Hierarchy culture are formalized and structured characteristics of organizational activities.

\section{Style of the organization leader}

To develop and maintain a culture, the leaders of an organization must function in a manner consistent with the existing or desired culture of the organization. Hence leadership styles are organized by culture types. Leaders of Clan culture act as mentors or parent figures of the organization and in Market culture they act as hard drivers, producers or competitors. Adhocracy culture leaders function as entrepreneurs, innovators or risk takers and in Hierarchy culture they show the signs of coordinators or organizers in their work.

\section{Organizational glue}

These are espoused values or accepted norms of the organization. Loyalty and traditions are key norms of the Clan culture while Market culture highlights the importance of goal accomplishment and production. Adhocracy culture values innovation and developments and in Hierarchy culture, every activity is governed by established rules and procedures of the organization.

\section{Nature of organizational climate}

This explains existing working environment of the organization. Climate of Clan culture is participative and comfortable while Market culture has a competitive and confrontational climate. Adhocracy culture has characteristic of readiness and Hierarchy culture emphasizes the state of performance and stability.

\section{Success criteria of the organization}

This indicates the relationship between organizational success and the core values of it as perceived by the employees of the organization. Clan culture believe that their success lies on the development of human resources while Market culture believes market penetration and existing market share as key reasons for their success. Adhocracy culture depends on project leaders to achieve success by implementing their innovative ideas. Hierarchy culture gives high weightage to smooth scheduling of organizational activities and strict time targets.

\section{Management style towards the employees}

For the effective development of a culture within an organization, there is a necessity to have closer relationship between style of management and culture types. Management competencies possessed by the leaders should be consistent with the culture of their organization. In Clan culture managers value teamwork, consensus and participation. Management style in Market culture is production oriented with incentives for achievement. In Adhocracy employees taste freedom, innovation and uniqueness. Employees of the Hierarchy culture show security of the job and predictability as their main concern.

\section{Data collection and analysis}

As described in section 2, "Competing Value Framework", developed by Quinn and Cameron was used as a model for measurement of organizational culture. The focus of the research was on entire organization rather than on units of the same. Nine contractor organizations and nine consultant organizations in Sri Lanka participated in the study. Sample was selected with the aim of representing all types of consultant and contractor organizations who are engaged in construction work. Hence, selection ranged from small scale to multi deciplinary construction organizations.

Data were collected from executive and non-executive employees of the organization from various divisions. Three executive employees and five non-executive employees were randomly chosen from an organization for personal interviews and questionnaire survey and this ratio was maintained throughout the study. The executives of these organizations have titles such as 
Divisional Head, Project Manager, and Company Director. In total 144 questionnaires and personal interviews were conducted equally for contractors and consultants.

The survey was carried out by obtaining prior appointments from the respondents and conducting the personal interview followed by the questionnaire survey. The objective of the personal interview is to solicit information related to the organization, which would be useful in explaining the results of the questionnaire survey. In the questionnaire, four statements were utilized for each element, with one statement representing each of the four culture types based on Competing Value Framework. Respondents were asked to distribute 100 points between the four statements for each element depending on how similar the description was to the organization in question. The points distributed to each of the statements for the cultural elements were averaged to determine an overall culture score.
The responses were presented in a tabulated form for each organization and summarized to obtain an overall score in view of comparing the overall culture of contractor and consultant organizations. Further, each element of organization culture was analyzed to determine the dominance and distribution of cultural types.

\section{Results of survey}

The results of analysis are presented under three headings as follows.

\subsection{Dominating culture types}

Table 1 summarizes the dominating culture type for the six elements under consideration. Dominating culture type is the one that obtained the highest value when respondents were asked to distribute 100 points among the statements representing the four culture types. Five out of six elements have Clan as the dominating culture type for consultants. All six elements of the contractors are dominated by Market culture.

Table 1: Dominating culture type in each element of the contractor and consultant organizations

\begin{tabular}{|l|c|c|c|c|}
\hline \multicolumn{1}{|c|}{ Cultural Element } & Clan & Adhocracy & Market & Hierarchy \\
\hline Dominant Characteristics & & & $\sqrt{ }$ & $\bullet$ \\
\hline Organization Leader & $\bullet$ & & $\sqrt{ }$ & \\
\hline Organizational Glue & $\bullet$ & & $\sqrt{ }$ & \\
\hline Organizational Climate & $\bullet$ & & $\sqrt{ }$ & \\
\hline Success Criteria & $\bullet$ & & $\sqrt{ }$ & \\
\hline Management of Employees & $\bullet$ & & & \\
\hline
\end{tabular}

- Consultant

\subsection{Competing culture types for each element}

Figures $2-7$ show the results for each of the six elements of the organizational culture considered in the study. Contractors perceive Dominant Characteristics of the organizations as strongly Market oriented (see Figure 2). This shows that the core values of the contractor organizations are oriented towards production-related strategies.

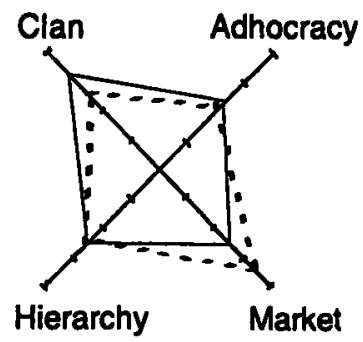

Consultant

Contractor

Fig 2: Dominant characteristics
The Organization Leaders of the consultants show a bias towards Clan Culture while the contractors organization leaders tend to move towards the Market Culture as in Figure 3 . This contrasting scenario explains that the leaders of consulting organizations are considered as mentors or parent figures while the leaders of contractor organizations are considered as hard drivers.

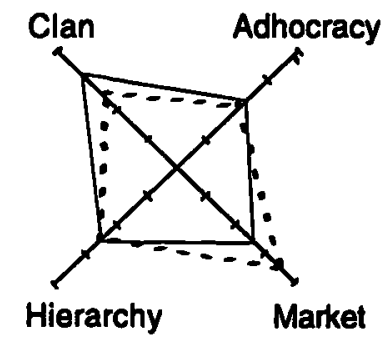

Consultant

Contractor

Fig 3: Organization leader 
Organizational Glue which indicates the espoused values of the organization also show similar results to organizational leader as given in Figure 4. This shows that consultants value traditions and loyalty while contractors value goal accomplishment and production. The Organization Climate of consultants is strongly biased towards Clan and Adhocracy Cultures, while contractors organization climate is biased towards Market and Adhocracy Culture types (see Figure 5). This shows that the working environment of consultants is participative and flexible. Further the working environment of contractors is considered as competitive and confrontational but flexible enough to provide room for innovativeness.

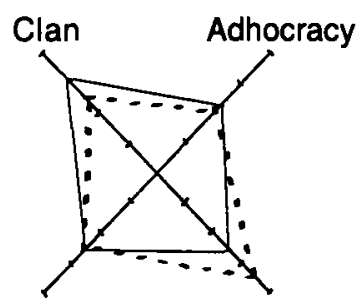

Hierarchy Market

Consultant ------ Contractor

Fig 4: Organizational glue

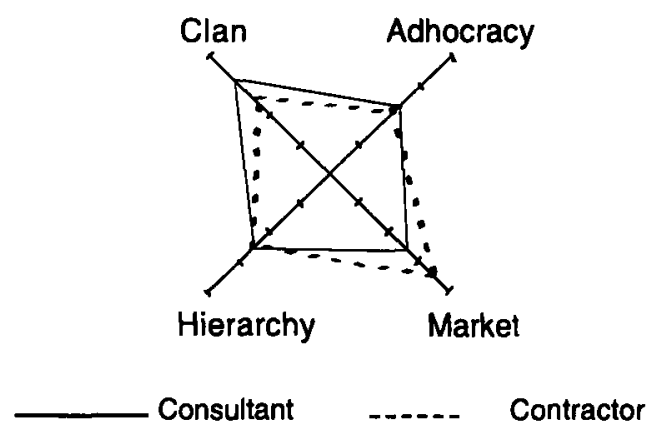

Fig 5: Organizational climate

The Success Criteria of consultants are perceived to be Clan oriented, while contractors Success Critria is Market oriented with an inclination towards Hierarchy as in Figure 6. This show that consultants believe that their success lies on the development of human resources. Contractors on the other hand, believe market penetration and market share as their success criteria with an added emphasis on smooth scheduling of organizational activities and strict time targets. The results for Management Style towards the employees, as given in Figure 7, shows a clear bias of Clan and Market culture types for consultants and contractors respectively. Consultants employ teamwork and participatory approach in managing their workers while contractors employ incentives for achievements.

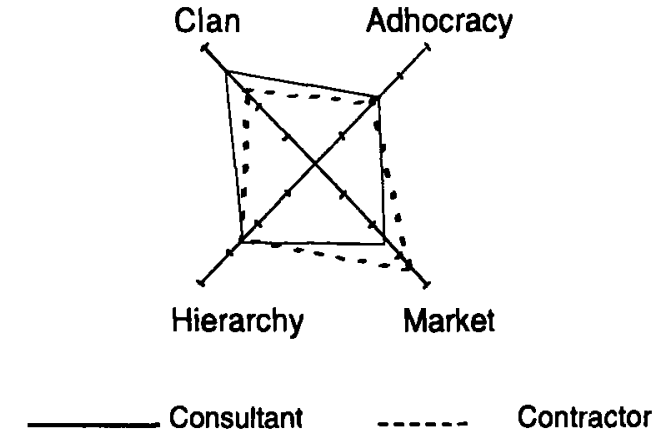

Fig 6: Success criteria

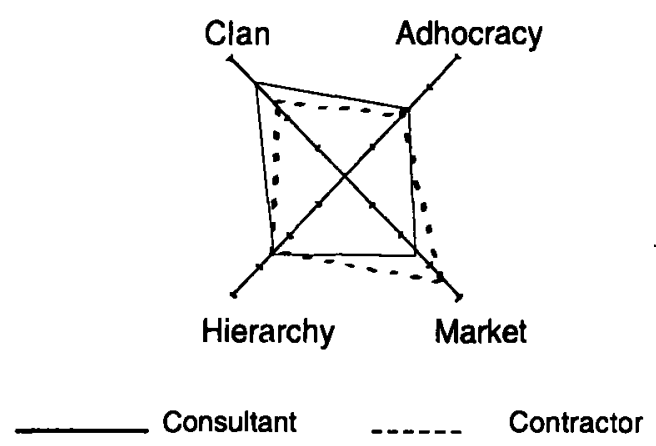

Fig 7: Management style

\section{$\underline{5.3 \text { Overall Culture }}$}

The overall culture profile, which is taken by averaging the six elements illustrates that the Consultants show a bias towards Clan culture while contractors are biased towards Market culture and both categories of organizations show similar affinity to Hierarchy and Adhocracy culture.Consultants prefer teamwork and rewards are based on group rather than individual. Consultants show preference for information sharing, participative and comfortable working environment. Contractors on the other hand, emphasize profit maximization and productivity. The competitive orientation towards rivals and emphasis on achievement make it quite opposite of consultant organizations. Similar affinity on competing values between Hierarchy and Adhocracy indicates that both contractors and consultants value entrepreneurship, innovation, coordination and organization of work in equal terms.

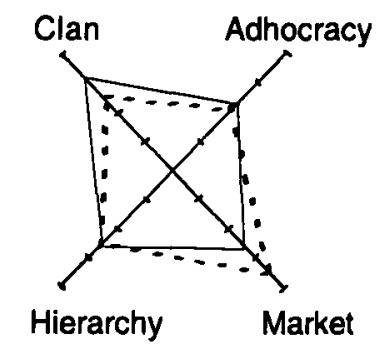

Consultant

Contractor

Fig 8: Overall culture profile 


\section{Discussion}

In order to test the hypothesis given in section 1 of this paper, first, within group characteristics are considered. Table 2 presents the mean values and standard deviation of the overall culture scores of these two types of organizations.

Consultants have the highest mean value for $\mathrm{Clan}$ and lowest for Market cultures. However the high standard deviation for Clan indicates the relative disagreement of ideas among consultants regarding their dominant culture. It appears that there were few who did not strongly beleive that the Consultants have a Clan dominant culture.
The statistical test indicate that at $99 \%$ level of confidence, the difference between the two entities lies somewhere between 6.4 - 8.3 for Clan, 0.7 - 1.7 for Adhocracy, 6.8 8.3 for Market, and 0.1 - 1.9 for Hierarchy.

It can be inferred from the above test that the difference between consultants and contractors is relatively low in Adhocracy and Hierarchy cultures. This difference is relatively high in Clan and Market cultures. This implies that there is a considerable difference between the cultures of consultant and contractor organizations and this could be explained as between Clan and Market cultures respectively. Thus the attributes that can be used to distinguish the two types of organizations can be given in Table 4.

Table 2: Within group characteristics

\begin{tabular}{|l|c|c|c|c|}
\hline & \multicolumn{2}{|c|}{ Consultants } & \multicolumn{2}{c|}{ Contractors } \\
\hline & Mean & Standard Deviation & Mean & Standard Deviation \\
\hline Clan & 30.2 & 3.3 & 22.8 & 3.1 \\
\hline Adhocracy & 24.2 & 1.6 & 23.0 & 1.6 \\
\hline Market & 22.5 & 1.9 & 30.0 & 2.7 \\
\hline Hierarchy & 23.1 & 2.7 & 24.1 & 3.1 \\
\hline
\end{tabular}

Contractors have their highest mean value for Market and lowest for Clan and Adhocracy cultures. Relatively moderate standard deviation for Market indicates less disagreementamong contractors on their dominant culture. Based on these within group characteristics, it can be concluded that consultants show a Clan dominated culture mix, while contractors show a Market dominated culture mix. The above inference could be made for contractors with high confidence than for consultants.

To answer the question "is there a difference between consultants and contractors with regard to their culture?" the difference between two sample means has been considered. It was assumed that the two sample means are normally distributed and hence the difference of two means are also normally distributed. Using the following formula, confidence interval for the difference between two means is calculated.

$\left(\mu_{a}, \mu_{b}\right) \pm$ zc s.e. $\left(\mu_{a} . \mu_{b}\right)$

Where

$\left(\mu_{a}, \mu_{b}\right)$ is the difference between the two sample means $c$ is the desired level of confidence

s.e. $\left(\mu_{\mathrm{a}} \mu_{\mathrm{b}}\right)$ is the standard error of the difference between two means, which is given by

$\left[\left(s_{a}{ }^{2 / n_{a}}-1\right)+\left(s_{b}{ }^{2 / n_{b}}-1\right)\right]^{1 / 2}$

Where $s$ and $n$ denotes the sample standard deviation and sample size respectively. $(n=144)$.

Table 3 provides the confidence interval for all four culture types at $95 \%$ and $99 \%$ levels.
Table 3: Difference between the two sample means

\begin{tabular}{|l|c|c|c|c|}
\hline & \multicolumn{2}{|c|}{$\begin{array}{c}95 \% \text { Confidence } \\
\text { Interval }\end{array}$} & \multicolumn{2}{|c|}{$\begin{array}{c}\text { 99\% Confidence } \\
\text { Interval }\end{array}$} \\
\hline Clan & 6.6 & 18.1 & 6.4 & 8.3 \\
\hline Adhocracy & 0.9 & 1.6 & 0.7 & 1.7 \\
\hline Market & 7.0 & 8.1 & 6.8 & 8.3 \\
\hline Hierarchy & 0.3 & 1.7 & 0.1 & 1.9 \\
\hline
\end{tabular}

Table 4: Main-distinguishing characteristics of Consultants and Contractors

\begin{tabular}{|l|l|}
\hline \multicolumn{1}{|c|}{ Consultants } & \multicolumn{1}{c|}{ Contractors } \\
\hline Leaders as mentors & Leaders as hard drivers \\
\hline Loyalty to the organization & Production related strategies \\
\hline Participative work environment & Market penetration \\
\hline Teamwork & Goal accomplishment \\
\hline Human resource development & Confrontational work environment \\
\hline Rewards based on group & Incentives for achievers \\
\hline
\end{tabular}

\section{Conculsions}

The analysis presented here confirms that there is a marked difference between organizational culture of consultants and contractors. The study revealed that consultants are oriented towards a Clan dominated culture mix, while contractors are oriented towards a Market dominated culture mix. 
Consultants believe their success lies in development of human resources for achieving specific goals of the organization. They emphasize on loyalty and traditions and create participative and comfortable working environment. Further, they highlight the importance of teamwork, encourage discussions, participative decision-making and open communication. Leaders of consultant organizations successfully play the role of mentor and guide subordinates towards a common objective.

Contracting organizations on the other hand, are driven towards output maximization. They encourage competitive workenvironment and emphasize on goal accomplishment. Leaders of contractor organizations are considered as hard drivers.

Both types of organizations have almost equal commitment to risk, innovation and development and face situations where tasks are not clearly defined despite sever deadlines. However there are instances, which totally fit with rules and procedures of the organization as well. Hence, both types of organizations agree with the importance of maintaining their internal system.

Shaping the business activities to meet the environments' needs is a prerequisite in any organization strategy. Hence, the difference between organizational culture of consultants and contractors and the attributes that lead to this difference are understandable. However, the prime concern is the prevalence of disputes and communication gap between these two groups in the industry and the question whether organizational culture aggravates this situation. Can organization culture be used to diffuse the tension between these two groups and as a result reduce disputes?

Further research is needed to address these issues and to find a solution to this pressing problem of construction disputes.

\section{References}

Bennet, J. Pothecary, E.\& Robinson, G. (1996). Designing and Building a World - Class Industry, Center for Strategic Studies in Construction, University of Reading.

Bowers, D.G. (1969). Work Organizations as Dynamic Systems, Technical Report, Institute of Social Research, University of Michigan.

Byar, L.L. (1987). Strategic Management Planning and Implementation: Concepts and Cases, $2^{\text {nd }}$ edition, New York: Harper \& Row.

Cameron, K.S. (1984). An Empirical Investigation of the Multiple Constituencies Model of Organizational Effectiveness, Working Paper Series 406, University of Michigan Business School.

Deal, T.E. \& Kennedy, A.A. (1982). Corporate Cultures: The Rites and Rituals of Cooperate Life, Addison-Wesley.

Egan, Sir J. (Construction Task Force) (1998). Rethinking Construction, DETR, U.K.
Fellows, R.F. Seymour, D. \& Hancock, M.R. (1994). Conflict Resulting From Cultural Differentiation: an Investigation of the New Engineering Contract, in, $P$. Fenn (ed.), Construction Conflict: Management and Resolution, CIB Publication 171, CIB, The Netherlands, pp. 259-268.

Fernando, N.P.N (2002). Effect of Communication Barriers in Construction Disputes, Unpublished Final Year Dissertation of the B.Sc. Quantity Surveying Department Building Economics, University of Moratuwa.

Harrison, R. (1972). Understanding Your Organization's Character, Harvard Business Review, May-June, 119-128.

Hofstede, G. (1984). Culture's Consequences: Intemational Differences in Work Related Values, London: Sage.

Hofstede, G. (1991), Cultures and Organizations, London: McGraw-Hill..

Latham Sir M. (1994). Constructing Team: Joint Review of Procurement and Contractual Arguments in the United Kingdom Construction Industry, London: HMSO.

Lundberg, C.C. (1990). Surfacing Organizational Culture, Journal of Managerial Psychology, 5(4):19-36.

Maloney, W.F. (1989). Organizational Culture: Implication for Management, Joumal of Management in Engineering, 5(2): 125-138.

Maloney, W.F. \& Federle, M.O. (1991). Organizational Culture and Management, Journal of Management in Engineering, 7(1): 43-57.

Maloney, W.F. \& Federle, M.O. (1993). Practical Models for Organizational Assessment,Journal of Management in Engineering, 9(1):64-81.

Quinn, R.E. (1988). Beyond RationalManagement: Mastering the Paradoxes and Competing Demands of High Performance, San Fransisco: Jossey-Bass.

Rameezdeen, R. \& De Silva, S. (2002). Trends in Construction Procurement Systems in Sri Lanka, Built-Environment Sri Lanka, 2(2):2-9.

Root, D. \& Hancock, M. (1996). Familiarity and Procurement Preference - Putting the Brake on the Adoption of New Procurement Methods, in Economic Management of Innovation, Productivity and Quality in Construction, Vol. 11, ClB W-55, Zagreb; 523-534.

Seymour, D. \& Rooke J. (1995). The Culture of the Industry and the Culture of Research, Construction Management and Economics, 13(6): 511-523.

Trice, H.M. \& Beyer, J.M., (1984). Studying Organizational Cultures through Rites and Rituals, Academy of Management Review, 9: 653669. 